\title{
Merit-Based Incentive Systems and the Problem of Productivity in Science and Technology in two Latin American Countries
}

\author{
Juan C. Escalante and Jaime Jiménez
}

Since the 1980s, individual merit-based incentive systems have been implemented in several Latin American countries to counter the negative effects of the economic crisis that swept the continent during that decade. The aim has been to allocate less funds to the academic community, while minimizing the rapidly increasing exodus of their most recognized scientists. In the following, we will examine to what extent this strategy was accomplished by the state, while at the same time responding to growing societal demands for more accountability from university/S\&T sectors. The cases of two Latin American countries, Mexico and Venezuela, are presented.

\section{The Economic Recession of the Eighties and its Impact on Science and Higher Education}

The economic crisis of the eighties represented a profound blow to most Latin American economies. This crisis was not anymore a recurrent, cyclical event. This time, the crisis represented the beginning of a deep, structural adjustment. The import-substitution model that had been adopted after WWII in part to thwart off future shortages of imported manufacturing goods from the then belligerent nations, was rapidly coming to the end of its cycle. Its most salient characteristics, protected internal markets, stable production, and fairly stable employment, were increasingly coming under scrutiny. The new model emerging out of this transition phase was very close to its opposite. The emphasis had shifted to free markets, flexible production, and globalization of economic life, all of which demanded modernization of industry, in terms both of equipment refurbishing, as well as logistics redesign and widespread introduction of soft technologies.

These conditions, however, were symptoms of a more serious problem. The economic development of the sixties and seventies has been described as "stagflation" (Vergara, 1993: 126), having 
the combined effects of both recession and inflation. As a consequence of the rise of neo-liberal ideology and policy, there was a severe contraction of the state resulting in drastic cutbacks of all government-supported programs. In Latin America, education and science and technology have been among these activities, as they depend heavily, if not entirely, on government funds.

This new orientation resulted in a paradoxical situation: in complying with neo-liberal principles, as mandated both by the World Bank and the International Monetary Fund (IMF) (Szentes, 1996), Latin American governments were compelled to cut precisely those social capital goods that had become the key factors in global market competitiveness: scientific research and its potential applications in marketable, value-added products, as well as education in general, i.e. those goods that are needed to recover from the crisis, and whose absence may be perceived, although perhaps indirectly, as its primary cause.

The effects of the cuttings were dramatic. In Mexico, for example, the federal government expenditures in S\&T as a percent of the Gross Internal Product rose from a minimum of 0.15 in 1970 to a maximum of 0.53 in 1984 to go back to 0.18 in 1987, indicating one of the lowest historical rates (Ballesteros, 1988:31). As regards the entire decade, from 1980 to 1990 , the expenditures were in 1990 lower than those in 1980 in real terms (Chavero, 1993: 103) ${ }^{1}$.

The situation with the education sector was also problematic. From 1983 to 1987 the total expenditure decreased by $2.6 \%$, with higher education suffering the greatest decrease, $10.2 \%$ in real terms (Vergara, 1993: 133). The share of edu- cation of total government expenditure fell down to $12.8 \%$ in 1985, when the respective figures were in 1977 and in 1979 $15.5 \%$ and $17.5 \%$. The share of education of the GIP has since 1990 never been higher than 3\% (Chavero, 1993: 97-98).

The trend has been similar all over Latin America. Drastic regression can be observed in the same areas in Venezuela, particularly in scientific research (Machado-Allison, 1996: 79). In terms of total government funds allocated to S\&T, public universities, where most scientific research is conducted, suffered a severe recession that decreased their share of public funds from $31.2 \%$ in 1978 to $10 \%$ in 1990. As regards the GIP, prior to 1983, investments in the S\&T sector were never over $0.5 \%$, and the trend has been decreasing since then (Vessuri, 1992: 2427). It is worth pointing out that these trends do not only reflect cuttings in real terms, as the rough figures reflect, but since the reduction shows a decrease in GIP percentages, they actually mean a redefinition of government priorities.

\section{Mexico and Venezuela as Examples of Latin American Experience}

Mexico and Venezuela serve as a focus of our analysis mainly because, among the Latin American countries that exhibit an academic community of any significant size, these two have developed in many respects in similar ways. Both of them have a common economic background, first as exporters of agricultural and mineral raw materials, and afterwards as countries with oil-based, mono-exporting economies. They have also shared a common ideology and policy instrumentation in the founding and evolution of their academic com- 
munities and infrastructures, although these differ in size and time frame.

As products of the so-called "American Enlightenment" that swept the continent in the second half of the 18th century and in the 19th century, Mexico and Venezuela elaborated scientific cultures and structures that centered on the idea of science representing the instrument par excellence to human progress and social well-being. In contrast to many of the more advanced nations, where science became a cultural phenomenon in its own right, evolving gradually as a consequence of its practitioners' close interaction with their own immediate environment, the majority of the new Latin American governments, in the midst of a struggle to create their new national identities, coopted these cultural expressions and transformed scientific activity into an act of the state.

The 19th century represented, after all, the end of Spain's 300 year-old colonial mandate over the vast majority of the Latin American nations. Science and scientific knowledge became a means to generate new citizens for liberated societies. In the process, however, the transformation of science from an eminently cultural activity into a political and ideological instrument, precluded any state support to "local" scientific activity, more linked to in-house problems and needs, including the production and provision of basic material goods. The end result was the establishment of a type of science policy whose main objective was to merely finance a permanent learning process in areas that, for the most part, were exclusively in the international scientific arena, scarcely related to local, cultural referents. This is why Saldaña (1992: 44-45) defines sci- ence policy in Latin America as having more of an educational character.

\section{The Developments in Venezuela}

Although the S\&T system in Venezuela did not come of age until the 1950s, the importance of education was emphasized in line with the "enlightened" tradition referred above. The Council for Scientific and Humanistic Development, that was created in 1958 to stimulate and coordinate research activity, is a case in point. Its objective was to serve as a liaison for the various institutions engaged in scientific activity. It would do this, however, by establishing programs to subsidize research and post-graduate scholarships, financing sabbaticals and short-term research programs abroad, contracting personnel to open new learning and research areas, and by improving laboratory facilities (Vessuri, 1992: 22). As can be observed, activities were more in line with the creation of a scientific infrastructure, with a manifest educational orientation.

Before that time, Venezuela's stock of scientific and technological output was completely marginal with respect to advanced countries (Vessuri, 1984: 12). In Vessuri's opinion, this may be due to the relatively comfortable position Venezuelan society enjoyed as a result of its enormous reserves of raw, exportable materials, principally oil. However, from 1950 , this stock of output began to grow exponentially, financially backed by the oil export income and justified to a great extent by the demands that post-war industrialization was placing on Venezuelan society. For years the image induced by policymakers had been that industrialization and diversification of produc- 
tion, meant unlimited demand for scientists, technicians, and managers that would join the state apparatus as agents of the country's modernizing program.

However, despite the incorporation of a social, utilitarian discourse in the country's scientific efforts, evidenced by the creation of the Center for Development Studies (CENDES) in 1960, the lack of any real links between the local scientific community and the world of material production, separated in practice scientific activities from local contexts, facilitating thereby dependency on the international scientific community (Vessuri, 1984: 21).

The creation of the National Council for Scientific and Technological Research (CONICIT) in 1967, represents the formal institutionalization of science in Venezuela, as scientific practice is understood in the advanced countries. Although this institution was first conceived as being societally orientated, it soon became the object of heated discussions strongly influenced by a group within the local community that was more inclined to uphold the international, universal character of science with no social or utilitarian goals and objectives. This community sought recognition, prestige and acceptance within the international scientific world, of which many of Venezuela's scientists were already a part by virtue of their own studies in prestigious institutions abroad.

\section{The Developments in Mexico}

In contrast to Venezuela, Mexico's history of science and technology began before the country became independent in 1821 , as its scientists were attracted by the ideas of "Enlightenment". However, with the political turmoil during the battle for the country's independence, the politicization of science disassociated scientists from practical economic activities and strengthened their close relationship with the state and the ideological tasks that aimed at nation building. In addition, Comte's positivism had a strong influence on the political leaders. It lead to the institutionalization of scientific education in 1867 when the Organic Law of Public Instruction was passed. It was thought that academic education would suffice to form a new society and to support the country's entrance into the group of independent, sovereign nations of the world. Scientific education was also regarded as providing an automatic route to social wellbeing.

The National Council for Science and Technology (CONACYT), a parallel to Venezuela's CONICIT, was created in 1970 as the culmination of a long series of previous attempts at institutionalizing science in Mexico. Although efforts at establishing an effective S\&T infrastructure were made consistently, they were confronted by insurmountable limitations. First, as in the case of Venezuela, the opposition of an academic elite with an exaggerated apprehension to any attempts to harness science into any type of utilitarian objective. Second, the entrepreneurial sector's almost total integration to the transnational productive sector, that precluded any need for locally generated scientific or technical knowledge.

Both in Venezuela and Mexico, an unsolicited local scientific community, and the community's own disdain towards any attempts of regulation, have 
led to its social isolation and, as a consequence, a high vulnerability to fluctuations in government spending. Accordingly, during economic crises the academic world has been regarded as a superfluous investment, being among the items in the state's official agenda that should bear the most drastic cutbacks.

\section{Individual, Merit-Based Incentives for Academic Personnel}

Even though neo-liberal policy compelled Latin American governments to accomplish drastic cuts in S\&T expenditures, among many others, there was still the problem of how to revitalize the economy. Market competition today ${ }^{2}$ is highly dependent on the degree to which marketable products are technologically integrated. Paradoxically, there is a need to increase S\&T investments, especially in the infrastructure (Smith, 1996: 52). However, the state has conceived the growing brain-drain of top-level academics as a more serious problem threatening entire scientific communities (Malo, 1992: 344). To prevent this, Latin American countries have implemented a system of incentives that has been based on the criteria of international recognition.

In the middle of the 1980s, specific incentives were used in a purposeful way (De Ibarrola, 1992: 351). Several Latin American countries constructed innovative mechanisms and corresponding institutional means to implement this strategy. In Mexico, the objectives were realized through the National System of Researchers (SNI), while in Venezuela the mechanism was called the System of Promotion to Researchers (SPI). Both systems aimed at three main objectives
(Malo, 1994: 344-345; González et al, 1994: 348):

- To encourage scientific and technological research through honorary distinctions and active (financial) support of researchers that merited such recognition.

- To prevent further drain of the researchers that would leave the system by undertaking professional activities outside the academia, or emigrate to other countries where research is regarded as a fundamental societal activity.

- To provide the basis for luring future prospects to the academic profession by offering attractive economic incentives, while ensuring a "critical mass" of qualified staff responsible for the formation of subsequent generations of researchers, thus also ensuring the community's own reproduction.

Evidently, these mechanisms were not geared in practice toward the retention of the entire academic community, nor could they be, given the severe budget limitations the entire S\&T system was being subjected to. Rather, in the words of De Ibarrola ( 1992:351):

It appears that... these policies are ori-
ented to identify a small number of
scholars of "quality" from an enormous
academic labor market... a small group
is being promoted while everyone else
is being de-motivated. In effect, like in the Merton's "Matthew Effect”, the policymakers allocated decreasing funds to a smaller number of researchers, i.e. to the best and the most productive ones. The "selected few" would be capable of reproducing and of expanding as a "quality" group in the midst of a large community that was 
being disqualified and demotivated as a result of a common evaluation procedure.

It is not clear what is expected of this "top echelon" within the academia. Implicitly, they are to oversee the link between research and teaching, to provide qualified higher education to more than a million students (as in the case of Mexico), and to solve the problems coming from the needs of national research and technological development. However, the community's de facto mission, as indicated by the evaluation procedures focused on individual incentives, is more linked to personal merits and achievements, loosely related to the needs of national development:

...doctorates obtained in prestigious institutions, publications in internationally refereed journals, quotations in the Citation Index, post-graduate dissertations, awards, patents, etc...What are we dealing with is a palpable, quantifiable academic productivity, as measured by international standards (De Ibarrola, 1992: 350).

Although quality criteria have been introduced and theoretically considered in evaluating the system, still, in many of the cases quantitative parameters have been the primary determinants in difficult, borderline cases (González et al., 1992: 361).

\section{Publications as Indicators of Excellence}

Our analysis of publishing data shows that the systems' performance has not quite been what it was held out to be. Therefore the following assumptions can be made:
- All citations in the SCI from these two countries are assumed to be authored only by the members of their respective individual incentive systems.

- Those scientists that do not publish and are in the incentive systems should not be there, and are therefore considered flaws in the system.

- Those scientists that do publish but are not members of the incentive systems should in theory be included, and are therefore also considered flaws in the system.

- Flaws are considered, due to their exceptional nature, statistically negligible.

- Thus, it is safe to assume that the members of the incentive systems are those and only those that publish all the internationally refereed papers.

- Results of the analysis do not consider the primary level of the system's candidate, since this category is of a more transient nature, utilized to detect future, promising researchers with potential, that contribute in no significant manner to the publishing rates. Statistics (see Figure 1) taken from Mexico's CONACYT data bank (based, in turn, on statistics taken from the Science Citation Index), indicate that since 1984, the year of the SNI's inception, productivity rates, based on approximate figures, have consistently deteriorated, going from an approximate 99 papers published per researcher per year in 1984, to a low of .51 papers in 1991, observing a slight recovery of .61 papers per researcher in 1995 (see Figure 1). In the figures, all publications recorded in any one year are assumed to have been elaborated during the prior year of active research. The same applies to Venezuela's data. 


\section{Mexico}

Fiaure 1. Researchers' Annual Productivitv in Mexico
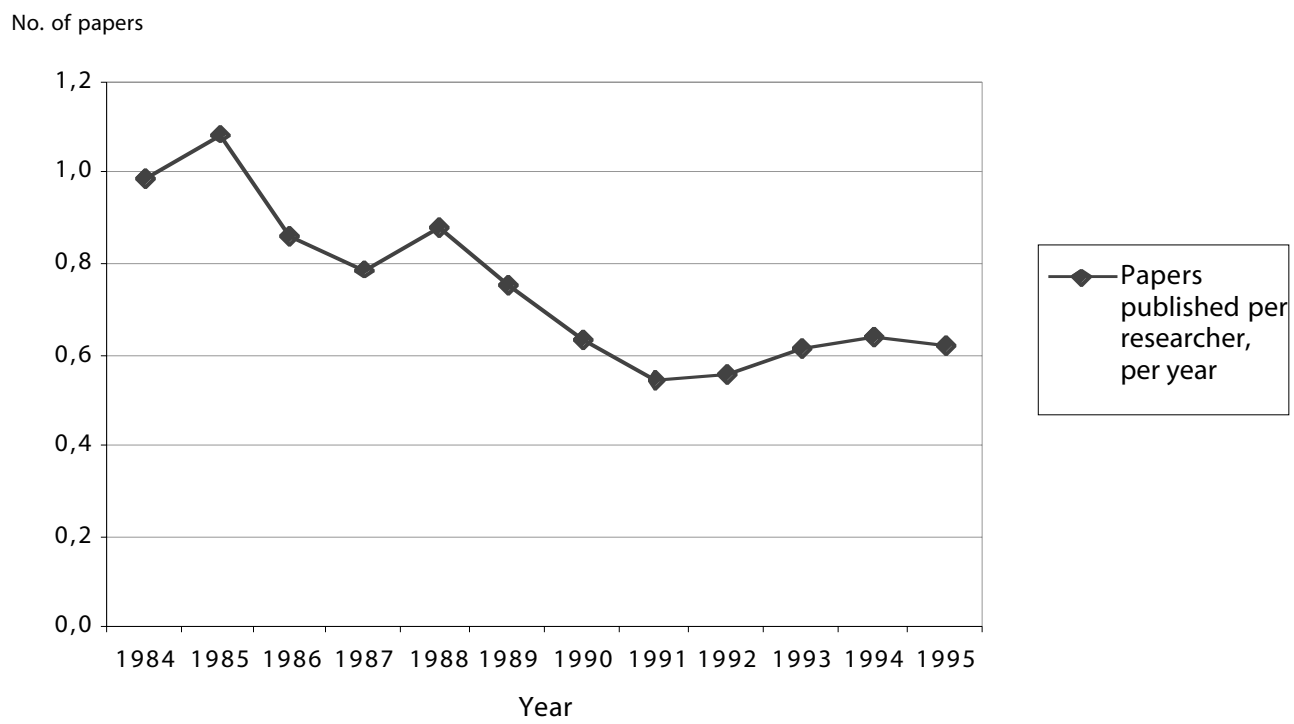

Figure 2. Mexico's Scientific and Technological System Indicators.

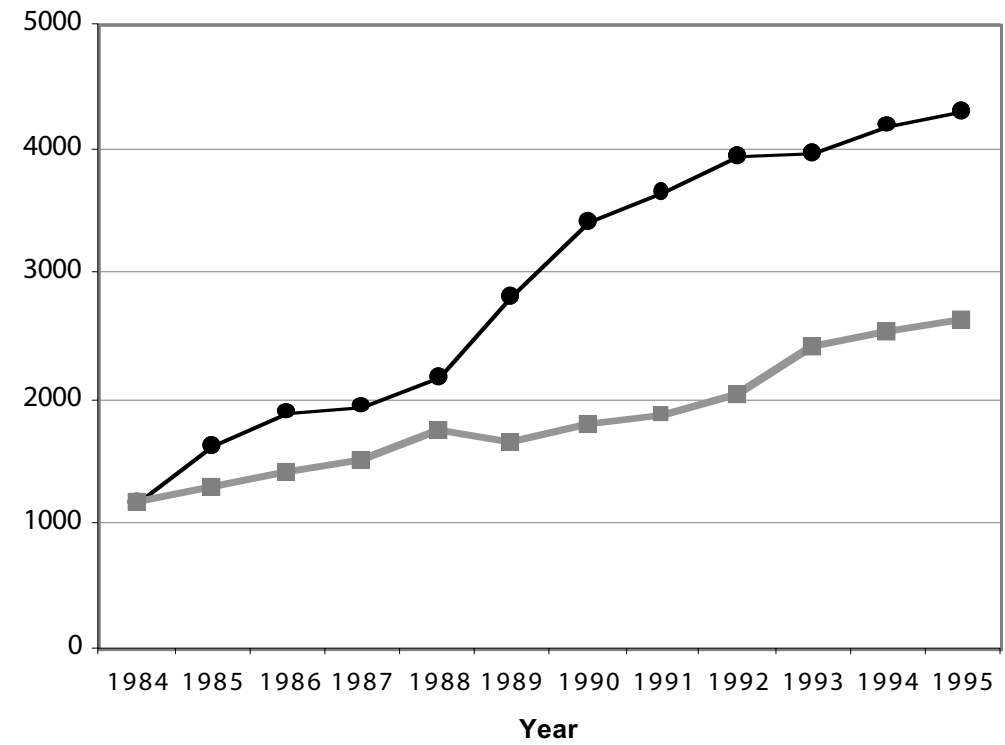

- No. of researchers

- No. of papers published 
A marked deviation is encountered from 1989 on, with respect to the prior relationship between the number of researchers in the system and the number of papers published (see Figure 2). The growth rate of researchers entering the system appears to increase at a faster pace than the corresponding rate of papers being published. That is, more researchers appear to be entering the system than papers being published.

It is uncertain at this time what this drop in productivity rates may be owed to. One possibility could be that different, other than quantitative factors were taken in to consideration at the time of evaluation for entrance and permanence within the system. Over the years, for example, standards have increased in terms of demanding a doctoral degree at the time of entrance into the system. There is no reason to believe, however, that this would bear negatively on existing productivity rates. On the contrary, the higher the academic degree held by the researcher, the more he is likely to publish. Whatever factors involved, which are certain to be matter for further study, it is clear that productivity ceased temporarily to be an overriding factor, as is evident in Figures 1 and 2, where the relationship seems to stabilize anew after 1993, although at about half of the productivity rate that was effective in the beginning of the program.

Venezuela follows a similar trend, as is shown in Figures 3 and 4, although without exhibiting such a marked deviation in the relationship. Indeed, although Venezuela's downward trend is not as marked as Mexico's, it can still be said that, in terms of increasing productivity, incentives have not had the impact expected at all. On the contrary, the trend shown in the figure demonstrates that at best, productivity rates have not changed in any significant way during the period considered. The last year for which data is available, 1995, shows a rate of .63, approximately the same rate as when the program began, in 1991 . González et al. (1996: 89) accurately point out that the data is indicative of the fact that there has been no significant increase in scientific productivity despite the apparent incentives provided to the scientific sector. In contrast to Mexico's data, however, there has been no significant drop either. In other words, we are able to assert that in Venezuela the incentives program has had no impact whatsoever on productivity, measured as the number of refereed papers published in international journals. Mexico's case, in contrast, shows that the incentives program has had a negative impact on productivity, measured with the same parameters. Evidently, as we have explored before, other factors are involved, which should merit further study.

The figures are too preliminary to make any final judgments at this time, and the rate of publishing is of course not the only factor involved in evaluation parameters for entrance or permanence within the system. Yet it is one of the most important ones. The "publish or perish" adage is very much present, as it would have to be if both Mexico and Venezuela are seeking to conform to international standards. And as we have said, many of the decisions within the system are, in the ultimate analysis, based on this parameter of all things being equal. But these results nevertheless point to the fact that at least the fulfillment of the first of the objectives re- 


\section{Venezuela}

Figure 3. Researchers' Annual Productivity in Venezuela
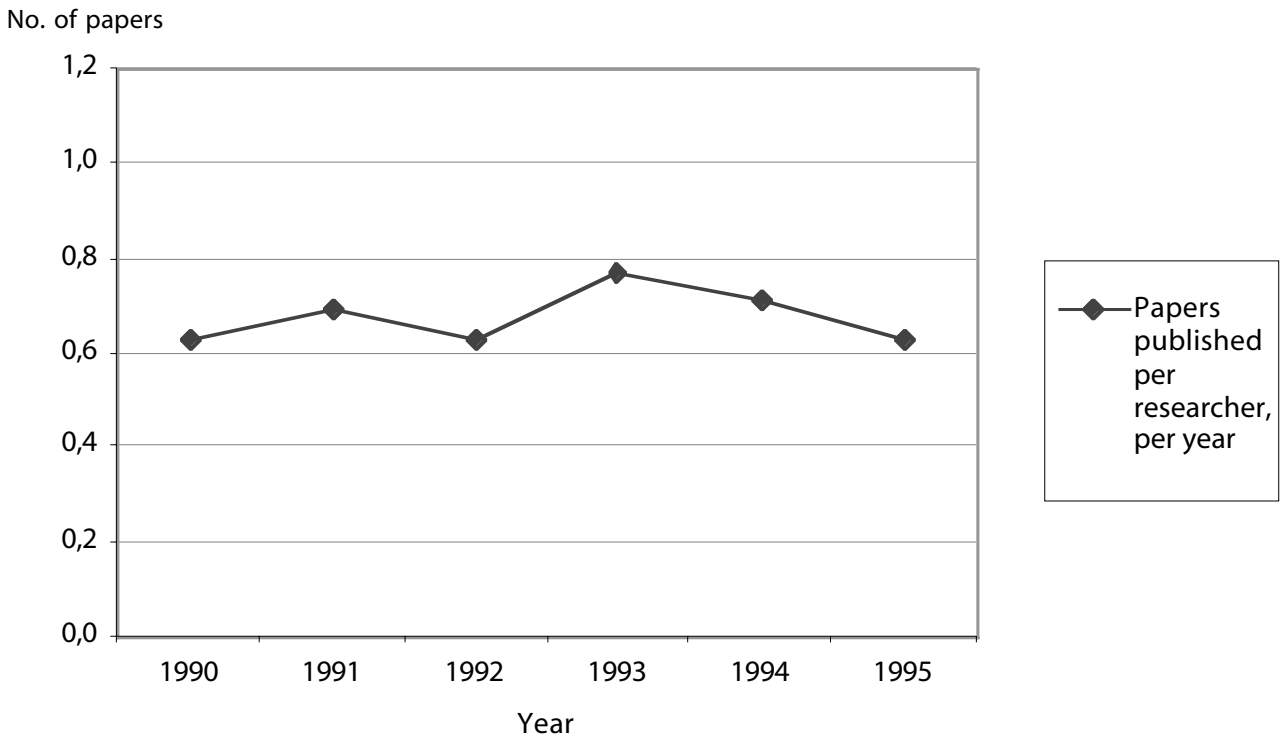

Figure 4. Venezuela's Scientific and Technological System Indicators.

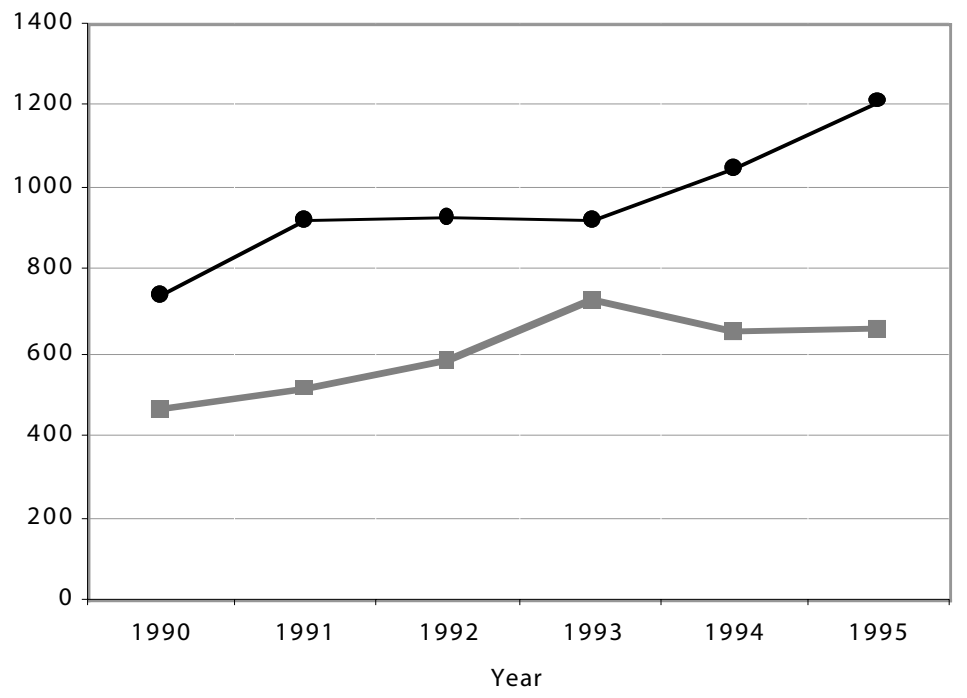

$\longrightarrow$ No. of researchers

- No. of papers 
ferred above, "To encourage scientific and technological research...", is at best in doubt.

Although several criticisms have been directed at the individual incentive systems (for a good listing, see Malo, 1992: 345-346), our largest preoccupation lies in the fact that the systems' bias to comply with international standards in terms of what is conceived to be academic output ("scientific credit" in Veronica StolteHeiskanen's (1987) terminology), is in effect discouraging researchers who are more inclined to direct efforts toward more locally based objects of study, which, perhaps justifiably so, tend to be of little or no interest to the world's scientific arena (Gibbs, 1995). For the Third World and its myriad of problems, that is quite a serious challenge.

\section{Conclusions}

Although it is recognized that a fundamental characteristic of science is its universal nature, and that the pursuit of knowledge for its own sake, and the desire to contribute to knowledge in general are legitimate goals of all scientific communities, we believe, that some sort of balance must be struck between the pursuit of these goals, and the search for a more localized type of knowledge that seeks to apply learning to some of the developing nations' most pressing problems. As we have seen, current academia's incentivation schemes largely emphasize an activity geared toward acceptance within internationally set standards and practices for scientific work. This, in fact, has led to the international recognition of some of our scientists. More weight should be placed on efforts to put that knowledge to work in the scientists' immediate, local, or national context. Under present conditions, academics cannot view such efforts but as something that can be done in their own free time, if at all, out of sheer vocation and interest. Most of the time, they are (pre)occupied with daily activities that are carried out or dropped in terms of what evaluation bodies require (De Ibarrola, 1992: 352).

The systems have accomplished improved living conditions for a small number of academics (for a good other number, it has meant no further deterioration of income) as well as some "social" recognition for scientists which, indeed, has enhanced the profession's self-esteem. But in terms of science, the results indicate that science is not being stimulated more than it was before the individual incentive mechanisms were implemented.

Little has been done, for example, in the way of alleviating some of these countries' most crucial problems, many of which could perhaps be explored conscientiously through scientific endeavor. Many of Israel's achievements in these areas, for example, are most likely not the result of having a scientific community that is solely concerned with keeping up with events occurring in the realms of "frontier" or international science. It would seem that achievements in the area of concrete applications are isolated, individually promoted events, that, with a more serious effort from funding organisms, such as the state, could go a much longer distance in solving today's critical problems. The use of genetic engineering for the improvement of seeds resistant to plagues, the finding of vaccines for local endemic maladies, treatment of residual waters to 
be used in agriculture, are just a few examples of the vast number of $R \& D$ topics of local interest geared towards the solution of the impinging problems proper of developing countries.

In terms of the second objective as posed by Malo and González, "To prevent further drain of researchers that would leave the system...", the incentive programs have had some impact. In the case of Mexico, at the end of the 1980's, an important part of the brain-drain took the form of students enjoying grants abroad, and failing to return after obtaining their PhD's. CONACYT started a repatriation program to retrieve these and other scholars in 1991, with positive results.

In terms of the third objective, "To provide the basis for luring future prospects to the academic profession..., although it would be fair to assert that programs such as the SNI and the SPI have gone a long way in providing the basis for the consolidation of a "critical mass" of scientific personnel, it is not at all clear whether it is actually playing any significant role in forming the future generations of scientific researchers. Given the Merton's Matthew effect, the younger generations are not being encouraged to join the profession.

The ability to take full advantage of the S\&T potential would require a concerted effort by those stakeholders that historically have had the closest relationship with S\&T activity: the state, the productive sector, and the scientific community itself. It is well known that the state has historically played a fundamental role in the promotion of science in advanced, industrialized countries that has gone beyond merely financing, as has been the case in most Latin
American countries, and has provided clear and concrete directives in line with goals geared for the general well-being, as Noble (1984) has so clearly described the case of the United States. In Latin America, in contrast, policy design and enactment has been pretty much left in the hands of a small "enlightened" scientific community even when that has meant no reference in general to local contexts and problems. The Latin American states would need, in order to re-assume their role as enactors of a people's collective goals, to begin by having clarity in what eventually might come to be a national project, one that goes beyond merely reacting to current global events, or attracting foreign investment.

\section{Notes}

1 Not surprisingly, the 1980s have generally been designated, Latin America's "lost decade". Among other things, the denomination refers to some type of rupture in the region's evolution whereby all social, political, and economic advances it had gained up to the end of the seventies suddenly began to lose ground. As it stands, at the end of the 90s, as economic crisis have become recurrent, this process of "losing" has not been reversed, and neither have the final public spending proportions shown for the beginning of the decade.

2 Clearly, the authors refer to an advantageous market competition, one whose derivative outcomes will tend to provide a general social good, such as raising the standard of living. That is, a market competition that goes beyond merely pricecompetition, which, in the developing countries, normally implies a low cost of labor. 


\section{References}

Ballesteros, C.

1989 La promoción estatal de la tecnología, Problematización de la política tecnológica de México en la década de los ochenta (State promotion of Technology, Problems of Mexico's technological policy in the eigties). FCPyS-UNAM and Friedrich Ebert Foundation, Mexico City.

Chavero González, A.

1993 "El financiamiento y la utilización de la ctividad científico-tecnológica en México (Funding and use of scientific and technological activities in Mexico)", in México : Ciencia y Tecnología, Adrián Chavero González (coord.), IPN-IIES-UNAM. Mexico City. De Ibarrola, $\mathrm{M}$.

1992 "México : la experiencia de homologar y deshomologar las remuneraciones al trabajo académico (Mexico : the experience of homogenizing and de-homogenizing remunerations in academic ork)", Interciencia, 17(6): 348353.

Gibbs, W.

1995 "Lost Science in the Third World", Scientific American, August: 76-83.

González, E., Bisiacchi, B., Viana di Prisco, G., and Di Prisco, M.C.

1992 "El programa de promoción del investigador en Venezuela (The Program for the Promotion of the Researcher)", Interciencia, 17(6): 358-365.

González, E., Arévalo, C., and Velasco, M.

1996 "Programade promoción del investigador (PPI) en Venezuela : ¿Reconocimiento o estímulo ?", (Program for the promotion of the researcher (PPI) in Venezuela : Recognition or incentive?). Interciencia, 21(2).
Guevara González, I.

1993 "La educación tecnológica frente a la modernidad (Technological Education in face of modernity)", in Enfoques Multidisciplinarios de la cultura científico-tecnológica en México, María Luisa Rodríguez Sala y José Omar Moncada Maya, Unam, Mexico.

Malo, S.

1992 "El Sistema Nacional de Investigadores de México (The National System of Researchers in Mexico)", Interciencia, 17(6): 344-347.

Noble, D.

1984 Forces of Production, a Social History of Industrial Automation, Oxford University Press, New York.

Saldaña, J.J.

1922 "Acerca de la historia de la ciencia nacional", (About the History of National Science), Introd., in Los Orígenes de la ciencia nacional (The Origins of National Science), J.J. Saldaña, editor, Cuadernos de Quipu, 4. Mexico, City.

Smith, B.

1996 "The accountability of Science", Minerva 34: 45-56.

Stolte-Heiskanen, V.

1987 "National and International Orientations of Science of Small Countries", Science Policy Studies from a Small Country Perspective. Edited by V. Stolte-Heiskanen, Publications of the Academy of Finland, Helsinki.

Szentes, T.

1996 Structural Adjustment in the Contemporary World Economy : the case of Hungary, Colección El Mundo Actual : Situación y Alternativas, Centro de Investigaciones Interdisciplinarias en Ciencias y Humanidades, UNAM, Mexico City. 
Vergara Reyes, D.

1993 "La investigación científico-tecnológica en México y su aplicación en la producción en la década de los ochenta. (Scientific-technological research in Mexico and its application to production processes in the eighties)", in México : Ciencia y Tecnología, Adrián Chavero González (coord.), IPN-IIESUNAM. Mexico City.

Vessuri, $\mathrm{H}$.

1984 "La formación de la comunidad científica en Venezuela" (The emergence of the scientific community in Venezuela), Introd., in Ciencia Académica en la Venezuela Moderna (Academic Science in Modern Venezuela), Hebe Vessuri, editor,. Acta Científica Venezolana, Caracas.

1992 "Ciencia, tecnología y modernización en Venezuela (Science, Technology and Modernization in Venezuela)", in La Ciencia en Venezuela : pasado, presente y futuro, Cuadernos Lagoven, Caracas.

Juan C. Escalante and

Jaime Jiménez

Institute for Research in Applied

Mathematics and Systems

National Autonomous University of

Mexico, Mexico 